\title{
Modelling of wetting tests for a natural pyroclastic soil
}

\author{
Mariagiovanna Moscariello ${ }^{1}$, Sabatino Cuomo ${ }^{1, a}$, Diego Manzanal ${ }^{2}$, Vito Foresta and Manuel Pastor ${ }^{2}$ \\ ${ }^{1}$ University of Salerno, Department of Civil Engineering Laboratory, of Geotechnics, Italy \\ ${ }^{2}$ Universidad Politecnica de Madrid, Department of Applied Mathematics and Computer Science, Spain
}

\begin{abstract}
The so-called wetting-induced collapse is one of the most common problems associated with unsaturated soils. This paper applies the Modified Pastor-Zienkiewicz model (MPZ) to analyse the wetting behaviour of undisturbed specimens of an unsaturated air-fall volcanic (pyroclastic) soil originated from the explosive activity of the Somma-Vesuvius volcano (Southern Italy). Both standard oedometric tests, suction-controlled oedometeric tests and suction-controlled isotropic tests are considered. The results of the constitutive modelling show a satisfactory capability of the MPZ to simulate the variations of soil void ratio upon wetting, with negligible differences among the measured and the computed values.
\end{abstract}

\section{Introduction}

The soils which exhibit a reduction in volume upon wetting at a constant total stress are called collapsible soils [1]. These soils generally experience three distinct stages of deformation during the wetting process: i) at high suction, a large decrease in suction generates a small reduction of soil volume; ii) at intermediate suction, soil wetting produces a significant volumetric reduction; iii) at low suction, further reductions of suction do not generate additional volume reduction. Collapsible soils are widespread in many parts of the world and they cause significant engineering problems, which range from a poor performance of foundations to the triggering of rainfall-induced landslides.

Soil collapse is influenced by several factors, i.e. the initial void ratio, the confining pressure, the initial matric suction. For this reason, a comprehensive investigation of the soil collapse behaviour should be performed through different types testing procedures, such as oedometer and triaxial tests [2].

The quantitative simulation of the soil collapse requires the use of advanced constitutive models, capable to deal with the hydro-mechanical behaviour of unsaturated soils. It is worth mentioning the Basic Barcelona Model [3] and the Wheeler-Sivakumar model [4], both based on the Classic Plasticity Theory [5]. The Generalized Plasticity-based model, proposed by Pastor et al. [6], represents an efficient alternative approach. The main advantage of Generalized Plasticity models is the ability to reproduce the stress strain behaviour of several types of soil with a good accuracy under both monotonic and cyclic loads, while not requiring the explicit definitions of yield and plastic potential surfaces [7]. Some modifications were later introduced to improve the

\footnotetext{
a Corresponding author: scuomo@unisa.it
}

capability of the original PZ model, by introducing a state parameter to incorporate the dependence of the flow rule and the plastic modulus on void ratio and confining pressure $[8,9,10,11]$.

In this paper, the Modified Pastor-Zienkiewicz constitutive model for unsaturated soils (MPZ) [11] is used to simulate the collapse behaviour of undisturbed specimens of a natural unsaturated air-fall volcanic (pyroclastic) soil of Southern Italy. The collapse is analyzed through three series of wetting tests and the predictive capability of the model is investigated.

\section{Material}

The paper deals with an unsaturated air-fall volcanic (pyroclastic) soil of Southern Italy, originated from the explosive activity of the Somma-Vesuvius volcano [12]. In particular, the pyroclastic deposits mantling the Pizzo d'Alvano massif have been extensively tested after the huge flowslides occurred in May 1998, which damaged four towns at the toe of the massif [12]. The laboratory tests selected for the calibration and validation of the constitutive MPZ model were carried out on undisturbed specimens, sampled in two tests areas, Sarno and Quindici, two small cities both damaged in 1998 [12].

The tested soil is classified as "Class A ashy soil" by Bilotta et al. [13], and is the class of the finest ashes present at this study area. The grain size distribution consists in 1.1 to $6.4 \%$ Gravel, 40.6 to $51.3 \%$ Sand, 40.9 to $53.61 \%$ Silt, 1.4 to $4.7 \%$ Clay [14]. The soils is characterized by very low dry unit weight $\left(\gamma_{\mathrm{d}}\right)$ and high void ratio $(e)$. In particular, $\gamma_{\mathrm{d}}$ ranges from 6.93 to 8.65 $\mathrm{kN} / \mathrm{m}^{3}$, while $e$ ranges from 2.595 to 1.982 . In addition, the soil has a metastable behaviour in triaxial tests [14]. 
The Water Retention Curve (WRC), which relates the degree of saturation $\left(S_{\mathrm{r}}\right)$ to the matric suction, is available from previous experiments performed through both Volume-Extractor and Suction-Controlled-Oedometer, (Fig. 1) on specimens sampled at Sarno site and characterized by different void ratios [13]. In particular, the WRC is well described by the Van Genuchten model, with parameters $\alpha=0.19 \div 1.02, \quad \mathrm{n}=1.19 \div 1.79$, and $\mathrm{m}=0.16 \div 0.44[13]$.

The soil mechanical behavior was formerly investigated both in saturated and unsaturated conditions, as well as during the transition from unsaturated to saturated condition. In this paper, some literature tests will be used, whose main results are hereafter described, while specific details are provided in the references quoted below.

Soil collapsibility was investigated by Bilotta et al. [14] using different devices and testing procedures. In particular, suction-controlled wetting triaxial (ISO and Triaxial) and oedometric (SCED) tests were performed starting from an initial suction of $50 \mathrm{kPa}$. In addition, wetting tests were perfomed using the standard oedometer (ED) on specimens at natural water content corresponding to about $50 \mathrm{kPa}$. The stress paths performed were oedometric $\left(k_{0}\right)$, isotropic $(\eta=0)$ and triaxial $(0.73<\eta<1)$, while the suction reduced in two manners: either gradually increasing the pore water pressure at the bottom of the specimens (test type: SCED, Triaxial and ISO) or suddenly flooding the specimen with distilled water (tests type: ED).

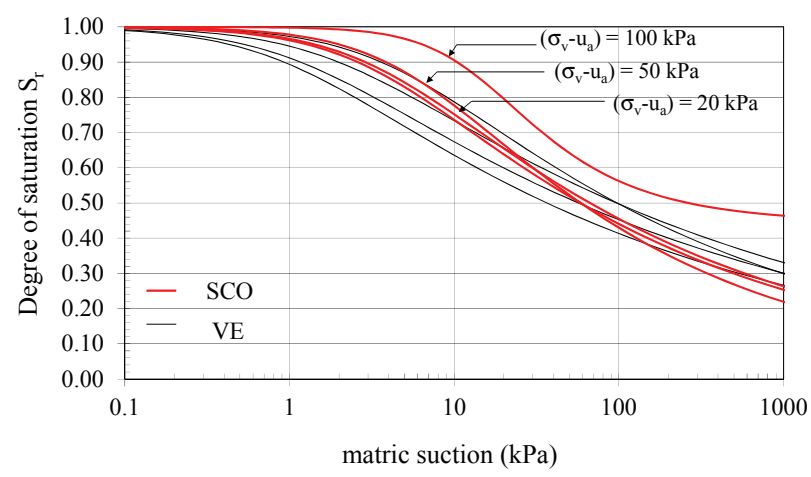

Figure 1. Water Retention Curve (WRC) of the tested material; SCED: Suction Controlled Oedometer and VE: Volume Extractor (modified from Bilotta et al. [13].

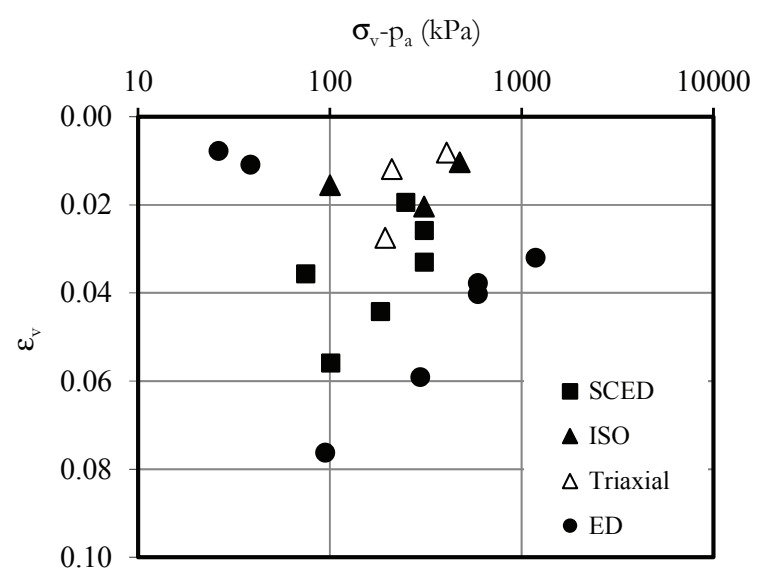

Figure 2. Results of wetting collapse tests on undisturbed specimens (modified from Bilotta et al. [14]).
Table 1. Oedometeric and isotropic tests performed on soil specimens (Sarno site) at initial suction $\left(p_{\mathrm{a}}-p_{\mathrm{w}}\right)$ of $50 \mathrm{kPa}$, and at a fixed value of net vertical stress $\left(\sigma_{\mathrm{v}}-p_{\mathrm{a}}\right)$, while the suction was decreased until zero.

\begin{tabular}{clcccc}
\hline Test type & Test & $e_{0}$ & $e_{\mathrm{w}}$ & $\begin{array}{c}\left(\sigma_{\mathrm{v}}-p_{\mathrm{a}}\right) \\
(\mathrm{kPa})\end{array}$ & $\varepsilon_{\mathrm{v}}$ \\
\hline \multirow{5}{*}{ SCED } & ESA13_03 & 2.537 & 2.2295 & 95 & 0.068 \\
& ESA9_03 & 1.992 & 1.860 & 295 & 0.044 \\
& ESA10_04 & 1.902 & 1.827 & 500 & 0.026 \\
\hline \multirow{5}{*}{ ISO } & USP6_06 & 2.217 & 2.167 & 100 & 0.016 \\
& USP1_07 & 1.889 & 1.830 & 311 & 0.020 \\
& USP3_06 & 1.762 & 1.734 & 477 & 0.010 \\
\hline \multirow{5}{*}{ ED } & ESL7_03 & 2.513 & 2.245 & 95 & 0.076 \\
& ESL9_03 & 2.245 & 2.053 & 297 & 0.059 \\
& ESL11_03 & 1.881 & 1.765 & 594 & 0.040 \\
\hline
\end{tabular}

$e_{0}$ initial void ratio; $e_{\mathrm{w}}$ void ratio after wetting; $\left(\sigma_{\mathrm{v}}-p_{\mathrm{a}}\right)$ net vertical stress; $\varepsilon_{\mathrm{v}}$ volumetric strain after wetting.

Figure 2 reports the experimental results. The magnitude of soil collapse was strongly influenced by the initial void ratio, the stress level at the beginning of the wetting stage and the type of test performed, which influence in turn the stress path followed. This complex mechanical behaviour requires specific constitutive models to be quantitatively reproduced.

The paper focuses on a series of 9 tests performed on undisturbed specimens and carried out through standard oedometer, suction-controlled oedometer and suctioncontrolled triaxial apparatus. Three vertical net effective stresses were selected $(100,300$ and $500 \mathrm{kPa})$, and the principal details of the tests are reported in Tab. 1 .

\section{Theoretical framework}

The Generalized Plasticity Theory, introduced by Pastor and Zienkiewcz [6], is particularly suitable to describe the behaviour of either loose or dense granular soils, both in drained and undrained conditions, even along complex stress paths. The original PZ model was fully defined through: i) the elastic constitutive tensor; ii) three directions (the loading direction and the plastic flow directions); iii) two scalars (the plastic moduli). This original framework was extended to unsaturated sands subjected to large variations of both relative density $\left(D_{r}\right)$ and confining pressure $\left(p^{\prime}\right)$ [11]. Later, the MPZ model introduced a state parameter to reproduce the behaviour of a given sand with different densities or subjected to different confining pressures with a unique set of constitutive parameters $[15,16]$. Particularly, the main modifications concerned: i) the dependency of dilatancy on soil relative density and confining pressure; ii) the yield surface associated with state parameter existing in an explicit or implicit form; iii) the dependence of isotropic plastic modulus on relative density variation.

The state parameter $(\psi)$ represents the relationship between relative density, void ratio and confining pressure. In other words, the state parameter describes the relative position on the e-p' plane of the current state and the projection of the CSL. Therefore, the description of CSL is much important. The MPZ model considers the 
formulation proposed by $\mathrm{Li}[17]$, Eq. 1, where $e_{\Gamma}$ is the void ratio at atmospheric pressure $\left(p_{a t m}\right), \lambda$ is the solpe of the CSL in $e-\left(p^{\prime} / p_{\text {atm }}\right)^{\xi}$ plane, $e$ and $p^{\prime}$ are the void ratio and the confining pressure at critical state. The flow rule depends on the relative density and, therefore, on the state parameter [7]. The dilatancy equation (Eq. 2) used in the model is that proposed by $\mathrm{Li}$ and Dafalias [18] where $M_{\mathrm{g}}$ is the slope of the Critical State Line in the $q-p$, plane, $\eta$ is the ratio between the mean effective stress $p$, and the deviatoric stress $q, \mathrm{~d}_{0}$ and $\mathrm{m}$ are material parameter of dilatancy law.

The parameter $M_{\mathrm{f}}$ (Eq. 3) is a function of the model constants $h_{1}$ and $h_{2}$, the parameter $M_{\mathrm{g}}$ and the ratio between the current void ratio $e_{0}$ and the void ratio at critical state $e_{\text {crit }}$.

The plastic modulus $(H)$ is a function of the state parameter and the confining pressures (Eq. 4), where $H_{0}$ and $\beta_{0}{ }_{0}$ are constitutive parameters. $H_{\mathrm{DM}}$ is a function which incorporates the material memory into the plastic modulus equation.

Finally, the elastic shear modulus and bulk modulus are assumed depending on confining pressure and void ratio, using the relation proposed by Richart et al. [19].

$$
\begin{array}{r}
e_{c r i t}=e_{\Gamma}+\lambda\left(\frac{p}{p_{a t m}}\right)^{\xi_{c}} \\
d=\frac{d_{0}}{M_{g}}\left(M_{g} \exp ^{m \psi}-\eta\right) \\
M_{f}=M_{g}\left[h_{1}-h_{2}\left(\frac{e_{0}}{e_{c r i t}}\right)\right] \\
H=H_{0}^{\prime} \exp \left(-\beta_{0}^{\prime}{ }_{0} \psi_{q}\right) \cdot \sqrt{p^{\prime} \cdot p^{\prime}{ }_{a t m}} \cdot H_{D M}
\end{array}
$$

The Generalized Plasticity state parameter-based model for unsaturated soils is formulated in terms of effective stress tensor as proposed by Bishop [20]:

$$
\boldsymbol{\sigma}_{i j}^{\prime}=\boldsymbol{\sigma}_{i j}-p_{a} \cdot \boldsymbol{\delta}_{i j}+S_{r e} \cdot\left(p_{a}-p_{w}\right) \cdot \boldsymbol{\delta}_{i j}
$$

where $\sigma_{\mathrm{ij}}$ is the total stress tensor, $p_{\mathrm{a}}$ is the pore air pressure, $p_{\mathrm{w}}$ is the pore water pressure, $p_{\mathrm{a}}-p_{\mathrm{w}}$ is the matrix suction $(s), S_{\mathrm{re}}$ is the relative degree of saturation and $\boldsymbol{\delta}_{\mathrm{ij}}$ is the Kronecker delta. In the triaxial plane, the Bishop equation is equal to:

$$
p^{\prime}=\bar{p}+\chi \cdot s
$$

where $\bar{p}$ is the net stress and $s$ is the suction.

In the model, the bonding parameter is introduced to take in account the effects of the suction due to capillary forces. The Critical State Line is defined starting from the equation proposed by $\mathrm{Li}$ and Wang [21], and is expressed by Eq. 8 , where $e_{\Gamma}, \lambda$ and $\zeta_{\mathrm{c}}$ are the same model parameters of the saturated MPZ model, while $\xi$ is the bonding parameter. $\xi$ is the product of two factor: the saturation degree of air $\left(1-S_{\mathrm{r}}\right)$, which represents the number of water menisci per unit volume of solid fraction, and the function of suction $\mathrm{f}(s)$, which accounts for the effect of the suction on the stabilising interparticle force exerted by a single meniscus. $g(\xi)$ is similar to a function proposed by Gallipoli et al. [22], which depends on the degree of saturation and suction (Eq. 8). Therefore, bounding parameter and the function $\mathrm{g}(\xi)$ define the dependence of CSL on matric suction.

The CSL in the $q-p$ ' plane depends on the relative degree of saturation $S_{\text {re }}$ (Eq. 10), which accounts for the residual degree of saturation $\left(S_{\mathrm{r} 0}\right)$ related to the adsorbed water.

The Water Retention Curve (WRC) is considered in the constitutive model in order to simulate the hydromechanical behaviour of unsaturated soils. In the model, the WRC is described through a modified version of the equation proposed by Fredlund and Xing [23]. In the equation (Eq. 12), the suction is replaced by the normalized suction (Eq. 12) that accounts for the void ratio dependency. It entails:

$$
\begin{gathered}
e_{c}=e_{\Gamma}-\lambda\left(\frac{p^{\prime}}{p_{\text {atm }}}\right)^{\varsigma_{c}}(1+g(\xi))^{-\varsigma_{c}} \\
g(\xi)=a[\exp (b \xi)-1] \\
p_{\text {CSunsat }}^{\prime}=p_{\text {CSsat }}^{\prime} \cdot \exp [g(\xi)] \\
S_{r e}=\frac{S_{r}-S_{r 0}}{1-S_{r 0}} \\
S_{r}=S_{r 0}+\left(1-S_{r 0}\right)\left\{\ln \left[\exp (1)+\left(\frac{s^{*}}{a_{w} \cdot p_{\text {atm }}}\right)^{n}\right]\right\}^{-m} \\
S^{*}=e^{\Omega} \cdot s
\end{gathered}
$$

where $s^{*}$ is the normalized suction, defined as a function of the void ratio $(e)$, the suction $(s)$ and a parameter of the model $(\Omega)$.

Globally, it is necessary to evaluate some additional parameters to predict the unsaturated behaviour: 3 parameter account the bonding due to suction ( $\mathrm{a}, \mathrm{b}$ and $\mathrm{c}$ ) and 5 or 9 parameter for accounting the water retention curve without and with hysteretic loop $\left(S_{\mathrm{r} 0}, \Omega, a_{\mathrm{w}}, a_{\mathrm{d}}, n_{\mathrm{w}}\right.$, $\left.n_{\mathrm{d}}, m_{\mathrm{w}}, m_{\mathrm{d}}, \beta_{\mathrm{w}}\right)$. These parameters can be obtained from the results of saturated and unsaturated laboratory tests.

\section{Constitutive modelling}

\subsection{Calibration}

The MPZ model is calibrated using the experimental 
results of isotropic and triaxial tests both on saturated and unsaturated soils, reported by Migliaro [24] and Lancellotta et al. [25]. Particularly, the constitutive parameters are respectively related to soil behaviour in: i) saturated conditions, such as for elasticity $\left(\mathrm{G}_{0}\right.$ and $\left.\mathrm{K}_{0}\right)$, Critical State $\left(M_{\mathrm{g}}, e_{\Gamma}, \lambda\right.$ and $\left.\zeta_{\mathrm{c}}\right)$, plastic flow $\left(\mathrm{h}_{1}, \mathrm{~h}_{2}, d_{0}\right.$ and $\mathrm{m})$, and plastic modulus $\left(\mathrm{H}_{0}, \beta,{ }_{0}, \mathrm{H}_{\mathrm{v} 0}\right.$, and $\left.\beta_{\mathrm{v}}\right)$, and ii) unsaturated conditions, such as bonding ( $\mathrm{a}, \mathrm{b}$ and $\mathrm{c}$ ), and water retention curve $\left(\mathrm{S}_{\mathrm{r} 0}, \Omega, \mathrm{a}_{\mathrm{w}}, \mathrm{a}_{\mathrm{d}}, \mathrm{n}_{\mathrm{w}}, \mathrm{n}_{\mathrm{d}}, \mathrm{m}_{\mathrm{w}}, \mathrm{m}_{\mathrm{d}}\right.$ and $\beta_{\mathrm{w}}$ ). The procedures adopted for the calibration of the constitutive parameters are explained.

The shear modulus $G_{\text {eso }}$ is obtained by fitting the initial slope in the $q-\varepsilon_{\mathrm{q}}$ plane ( $\varepsilon_{\mathrm{q}}$ is the distortional strain). The bulk modulus $K_{\text {evo }}$ is adjusted by fitting the initial slope of $p^{\prime}-\varepsilon_{v}$ curves obtained through drained triaxial tests carried out at initial confining pressures ranged between $50 \mathrm{kPa}$ and $100 \mathrm{kPa}$ and initial void ratios between 2.007 and 2.385 [24].

The parameters related to Critical State $\left(M_{\mathrm{g}}, e_{\Gamma}, \lambda\right.$ and $\left.\zeta_{\mathrm{c}}\right)$ are calibrated through triaxial tests performed on saturated soils and reported by Migliaro [24]. The tests show a hardening behaviour and do not reach any critical state, and it is difficult defining the CSL both in the $q-p$, and $e-p$ ' planes. Therefore, the CSL is drawn extrapolating the maximum deviatoric stress at a $40 \% \varepsilon_{\mathrm{q}}$. The $M_{\mathrm{g}}$ is calculated from the plot that relates the maximum (or critical) deviatoric stress to the corresponding mean effective stress of the drained triaxial tests. The $M_{\mathrm{g}}$ value is the maximum slope of the line that passed through the origin and better adjusted the experimental values.

The parameters $e_{\Gamma}, \lambda$ and $\zeta_{\mathrm{c}}$ are calibrated through the graph in the $e-\left(p^{\prime} / p_{a t m}\right)^{\zeta c}$ plane that relates void ratio and the corresponding mean effective stress at critical state of drained triaxial tests [24]. $\zeta_{\mathrm{c}}$ was chosen equal to 0.7 and then it is turned as proposed by Li and Wang [21].

The plastic flow parameters $h_{1}$ and $h_{2}$ are calibrated from the $q-p$ ' curves of undrained triaxial tests on loose saturated specimen carried out at initial mean effective pressure ranges between $50 \mathrm{kPa}$ and $100 \mathrm{kPa}$; this is done on the basis that the $M_{\mathrm{f}} / M_{\mathrm{g}}$ ratio approaches to 1.0 when the ratio $e / e_{\mathrm{CS}}$ reaches its lower limit.

The parameters related to dilatancy $\left(m, d_{0}\right)$ are evaluated through the drained triaxial tests already adopted for the calibration of $K_{\text {evo. }}$. The parameter $m$ was determined from the eq. 2, at the phase transformation point (between contractive and dilative behavior), where the dilatancy is nil. The state parameter and the stress ratio, which appear in the eq. 2 must be previously found taking into account the experimental data available in [24] and [25].

The initial tangent slope of the volume strain-shear strain curve $\left(d_{0}\right)$ is calibrated through drained triaxial compression, supposing that the elastic deformations were small and negligible, so the total strains were equal to the plastic strains. $d_{0}$ was calibrated through the method of the least square, fitting the experimental curve $d_{\text {exp }}-\varepsilon_{\mathrm{a}}$ and the model curve $d_{\bmod ^{-}}-\varepsilon_{\mathrm{a}}$.

The constant $H_{\mathrm{v} 0}, H_{0}$, and $\beta,{ }_{\mathrm{v}}, \beta{ }_{0}$ and $r_{0}-$ which measures the distance between the CSL and ISL (Isotropic State Line) in a saturated condition - were estimated by trial and error $[26,15,16]$ in saturated condition. The six constant parameters $\left(a_{\mathrm{w}}, a_{\mathrm{d}}, n_{\mathrm{w}}, n_{\mathrm{d}}, m_{\mathrm{w}}\right.$, $m_{\mathrm{d}}$ ) associated to the main drying and wetting curves are evaluate through the regression method proposed by Frendlund and Xing [23]. The WRC adopted for the constitutive modelling is labelled as $\mathrm{SCO} 3 \mathrm{~W}[50]$ by Bilotta et al. [13]. This curve was obtained at net vertical stress of $50 \mathrm{kPa}$ through the suction-controlled oedometer. The residual saturation degree $\left(S_{\mathrm{r} 0}\right)$ can be evaluated from the $S_{\mathrm{r}}-S^{*}$ curve. The parameter $\Omega$ is calibrated to obtain a unique $S_{\mathrm{r}}-S^{*}$ curve for specimen with different void ratio.

The bounding parameters $a$ and $b$ are calibrated through the void ratio of unsaturated and saturated soils at critical state. The calibration is performed on triaxial tests on saturated and unsaturated specimens. The experimental data available $[24,25]$ show that it is not possible to outline a clear direct relationship between the existence and location of the CSL in unsaturated conditions and the soil suction. The experimental data of saturated condition instead are the same adopted to calibrate the critical state parameters. The values of void ratio at critical state are computed through the procedure proposed by Gallipoli et al. [22]. The slope and the intercept of the CSL in $e-\ln \left(p^{\prime}\right)$ plane are defined through experimental data on saturated specimens. Then, the net stresses, the saturation degrees and the suctions at critical state are obtained through the triaxial tests performed on unsaturated specimens. These experimental values are adopted to calculate the bounding parameter $\xi$ and then $\mathrm{g}(\xi)$ at fixed values of $p^{\prime}$. The values of $\mathrm{g}(\xi)$ are compared with the ratio $e_{\mathrm{s}} / e$ obtained from experimental data. The parameter $c$ is calibrated through isotropic triaxial tests carried out at constant suction.

The parameters adopted for the constitutive modelling are partly taken from a previous calibration of MPZ made for saturated and unsaturated tests on pyroclastic soils [27, 28 ] and they are summarized in Tab. 2. The calibration of the MPZ model is carried out on three suction-controlled oedometric wetting tests performed at different net vertical stresses. The parameters are individuated through the procedures explained and then they are adjusted through a trial-and-error procedure. A unique set of parameters is capable to fit the volumetric strains experienced during the three tests (Fig. 3).

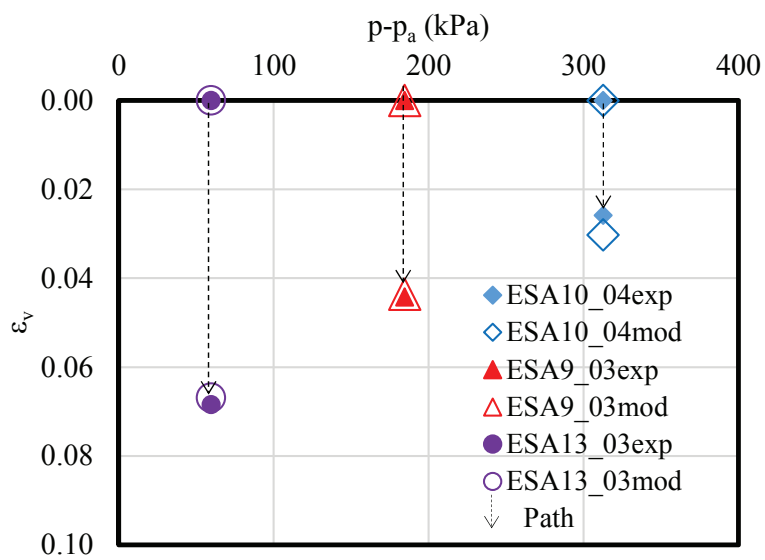

Figure 3. Experimental data (solid) and numerical results (empty) of the three suction-controlled oedometric wetting tests adopted for the calibration of MPZ model. 
Table 2. Constitutive parameters calibrated for the MPZ model.

\begin{tabular}{|c|c|c|c|c|c|c|c|c|}
\hline \multicolumn{2}{|c|}{ Elastic } & \multicolumn{4}{|c|}{ Critical State } & \multicolumn{3}{|c|}{ Bonding } \\
\hline$G_{0}$ & $K_{0}$ & $M_{\mathrm{g}}$ & $e_{\Gamma}$ & $\lambda$ & $\zeta_{\mathrm{c}}$ & $a$ & $b$ & $c$ \\
\hline 1286 & 1746 & 1.55 & 2.3 & 0.27 & 0.8 & 1.29 & 0.16 & 0.7 \\
\hline \multicolumn{5}{|c|}{ Plastic modulus } & \multicolumn{4}{|c|}{ Plastic flow } \\
\hline$H_{0}$ & $\beta_{0}^{\prime}$ & $H_{\mathrm{v} 0}$ & $\beta_{\mathrm{v}}$ & $r_{0}$ & $h_{1}$ & $h_{2}$ & $d_{0}$ & $\mathrm{~m}$ \\
\hline 30 & 1.1 & 20 & 2 & 1.44 & 1.0 & 0.35 & 0.8 & 2.5 \\
\hline \multicolumn{9}{|c|}{ Water Retention Curve } \\
\hline$S_{\mathrm{r} 0}$ & $\Omega$ & $a_{\mathrm{w}}$ & $a_{\mathrm{d}}$ & $n_{\mathrm{w}}$ & $n_{\mathrm{d}}$ & $m_{\mathrm{w}}$ & $m_{\mathrm{d}}$ & $\beta_{\mathrm{w}}$ \\
\hline 0.429 & 6.6 & 0.078 & 0.078 & 0.91 & 0.91 & 0.86 & 0.86 & 2 \\
\hline
\end{tabular}

\subsection{Validation and model performances}

Isotropic and oedometric wetting tests were simulated (Fig. 4), referring to one single set of constitutive parameters reported in Tab. 2. Three different values of net vertical stress are chosen: low $(100 \mathrm{kPa})$, intermediate $(300 \mathrm{kPa})$ and high $(500 \mathrm{kPa})$.

The tests at the same net vertical stress performed using different apparatus exhibit different volumetric strains. The isotropic wetting tests exhibit low values of volumetric strain, while the standard oedometric wetting tests experience high values of volumetric strain (solid markers in Fig. 4b). The reduction of void ratio during the wetting stage is also influenced by the stress path performed (Fig. 4a). The isotropic wetting tests experience the minimum variation of the void ratio. The manner of suction reduction influenced the magnitude of volumetric strain, while the variation of the void ratio is not influenced by the manner of the reduction of suction. The gradual reduction of the suction originated smaller volumetric strains than the sudden flooding. The net vertical stress influenced the volumetric strain, i.e. the specimens undergone at high net vertical stress exhibit the minimum variation of void ratio and the minimum volumetric strain.

The general agreement between the experimental results and the constitutive modelling is discussed with reference to $\varepsilon_{\mathrm{v}}-\left(p-p_{\mathrm{a}}\right)$ and $e-\left(p-p_{\mathrm{a}}\right)$ planes. The best numerical simulations in the two planes are obtained for the standard oedomeric tests. In terms of void ratio, the dif-

Table 3. Comparison among experimental and numerical physical variables of the tests simulated. All the variables are computed at the collapse.

\begin{tabular}{ccccc}
\hline Test & $e_{\exp }$ & $e_{\bmod }$ & $\left|e_{\bmod }-\mathrm{e}_{\exp }\right|$ & $\left|e_{\bmod }-\mathrm{e}_{\exp }\right| / e_{\exp }$ \\
& - & - & - & $(\%)$ \\
\hline ESA13_03 & 2.295 & 2.307 & 0.012 & 0.518 \\
ESA9_03 & 1.860 & 1.865 & 0.005 & 0.242 \\
ESA10_04 & 1.827 & 1.815 & 0.012 & 0.638 \\
\hline ESL7_03 & 2.245 & 2.249 & 0.004 & 0.189 \\
ESL9_03 & 2.053 & 2.057 & 0.004 & 0.204 \\
ESL11_03 & 1.765 & 1.766 & 0.001 & 0.394 \\
\hline USP6_06 & 2.167 & 2.158 & 0.009 & 0.395 \\
USP1_07 & 1.831 & 1.849 & 0.018 & 0.985 \\
USP3_06 & 1.734 & 1.738 & 0.005 & 0.264 \\
\hline
\end{tabular}

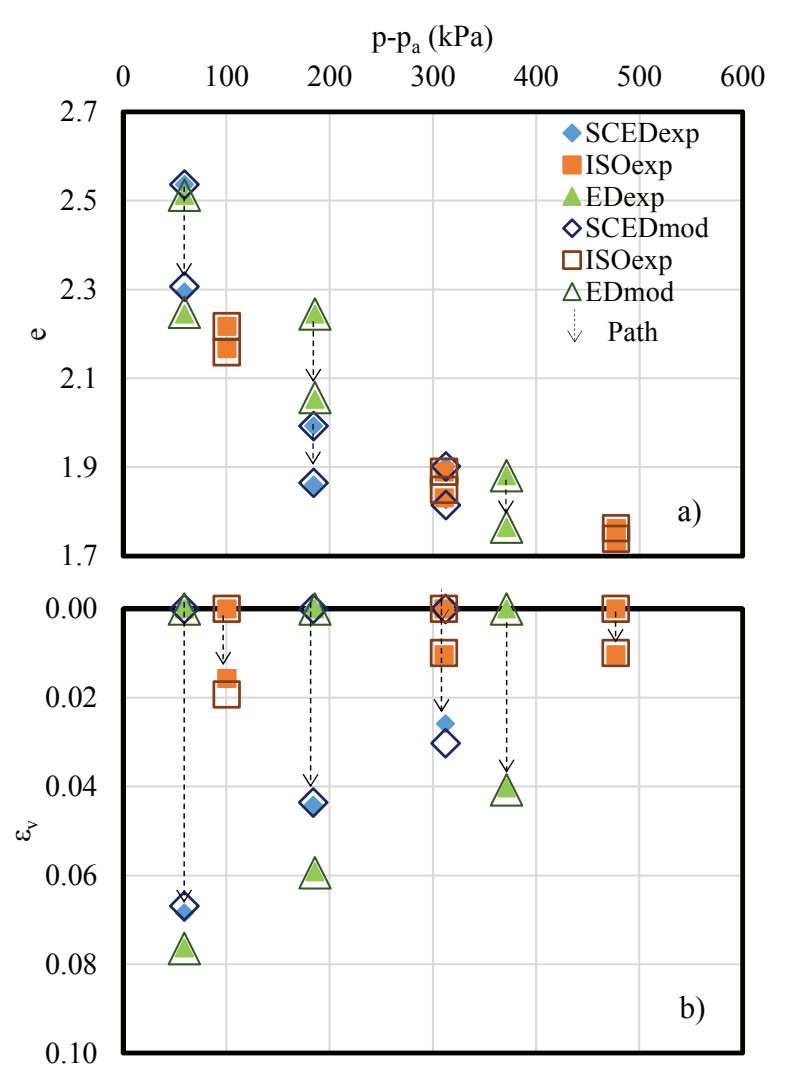

Figure 4. Comparison between experimental and numerical results in a) $\varepsilon_{\mathrm{v}}-\left(p-p_{\mathrm{a}}\right)$ plane and b) $e-\left(p-p_{\mathrm{a}}\right)$ plane.

ferences among measured and computed values are evaluated in absolute and percentage values (Tab. 3).

The minimum difference was equal to $0.039 \%$, the maximum difference was $0.985 \%$ and the average difference was $0.386 \%$. Therefore, the volumetric behaviour of the unsaturated pyroclastic soil in the wetting tests was excellently simulated by the MPZ model.

\section{Conclusions}

The paper dealt with the constitutive modelling of the mechanical behaviour of an unsaturated air-fall volcanic (pyroclastic) soil, originated by the explosive eruptions of the Vesuvius volcano in southern Italy. The wettinginduced collapse is analyzed through different type of tests: oedometric and isotropic tests. The capability of the constitutive model is evaluated with reference to the soil volumetric strain and the variation of void ratio.

It is highlighted that the MPZ model is capable to fit very well the void ratios and volumetric strains measured in the wetting tests. It is worth noting that this satisfactory simulation was performed by using a unique set of constitutive parameters. This peculiar feature of the MPZ model enhances the possibilities to reproduce realistic stress paths experienced by soil in boundary value problems.

Future researches should focus on the constitutive modelling of wetting tests in triaxial conditions along stress paths with non-zero deviatoric stresses. 


\section{References}

1. Pereira, J. H., \& Fredlund, D. G.. Volume change behavior of collapsible compacted gneiss soil. Journal of geotechnical and geoenvironmental engineering, 126(10), 907-916, (2000).

2. Vilar, O. M., and Davies G. I.. Collapse behavior analysis of a clayey sand using different testing procedures. Unsaturated Soils 2: 571-576, (2002).

3. Alonso, E.E., Gens, A., Josa, A. 1990. A constitutive model for partially saturated soils. Géotechnique, 40 No. 3: 405-430.

4. Wheeler, S. J., Sivakumar, V. An elasto-plastic critical state framework for unsaturated soil. Géotechnique, 45, No.1: 35-53, (1995).

5. Hill, R.. A variational principle of maximum plastic work in classical plasticity. The Quarterly Journal of Mechanics and Applied Mathematics, 1(1), 18-28, (1948).

6. Pastor, M., Zienkiewicz, O.C. and Chan, A.H.C. 1990. Generalized plasticity and the modelling of soil behaviour. International Journal for Numerical and Analytical Methods in Geomechanics, 14, 151190, (1990).

7. Manzanal, D., Merodo, J.A., Pastor, M. 2011. Generalized plasticity state parameter-based model for saturated and un-saturated soils. Part I: Saturated state. International Jour-nal for Numerical and Analytical Methods in Geomechan-ics, 35, Issue 12, 1347-1362, (2011).

8. Bahda, F., Pastor, M., \& Saitta, A.. A double hardening model based on generalized plasticity and state parameters for cyclic loading of sands. Numerical models in Geomechanics. The Netherlands, Rotterdam, 33-38 (1997).

9. Tonni, L., Gottardi, G., Simonini, P., Pastor, M., Mira, P.Use of Generalized Plasticity to describe the behaviour of a wide class of non-active natural soils. 3rd International Symposium on Deformation Characteristics of Geomaterials. Swets \& Zeiglinger Lisse, (2003).

10. Ling, H. I., and Yang, S.. Unified sand model based on the critical state and generalized plasticity. Journal of Engineering Mechanics (2006).

11. Manzanal, D., Fernández Merodo, J. A., \& Pastor, M.. Generalized plasticity theory revisited: new advances and applications. $17^{\circ}$ European Young Geotechnical Engineers Conference. (2006).

12. Cascini, L., Cuomo, S. and Guida, D.. Typical source areas of May 1998 flow-like mass movements in the Campania region, Southern Italy. Engineering Geology, 96, 107-125 (2008).

13. Bilotta, E., Cascini, L., Foresta, V., and Sorbino, G.. Geotechnical characterization of pyroclastic soils involved in huge flowslides. Geotechnical and Geological Engineering, 23: 365-402, (2005).

14. Bilotta, E., Foresta, V., Migliaro, G.. The influence of suction on stiffness, viscosity and collapse of some volcanic ashy soils. In Unsaturated Soils: Advances in Geo-Engineering, Toll et al. eds, (2008).
15. Manzanal, D.. Modelo constitutivo basado en la teorìa de la Plasticidad Generalizada con la incorporaciòn de paràmetros de estado para arenas saturadas y no saturadas, $\mathrm{PhD}$ thesis, Universidad Politecnica de Madrid, Spain, (2008).

16. Manzanal, D., Pastor, M., Merodo, J.A.F.. Generalized plasticity state parameter-based model for saturated and unsaturated soils. Part II: Unsaturated soil modeling. International Journal for Numerical and Analytical Methods in Geomechanics, 35 (18), 1899-1917, (2011).

17. Li, X. S. Modeling of dilative shear failure. Journal of geotechnical and geoenvironmental engineering 123.7: 609-616, (1997).

18. Li X.S., Dafalias Y.F.. Dilatancy for cohesionless soils. Géotechnique, 50, No.4, 449 -460, (2000).

19. Richart, F. E., Hall, J. R., Woods, R. D.. Vibrations of soils and foundations, Prentice-Hall (1970).

20. Bishop AW. The principle of effective stress. Tek Ukeblas; 39:859-863 (1959).

21. Li, X.S., Wang, Y.. Linear representation of steadystate line for sand. Journal of Geotechnical and Geoenviromental Engineering, 124, No. 12, 12151217, (1998).

22. Gallipoli, D., Gens, A., Sharma, R., \& Vaunat, J.. An elasto-plastic model for unsaturated soil incorporating the effects of suction and degree of saturation on mechanical behaviour. Géotechnique., 53(1), 123-136, (2003).

23. Fredlund, D. G., \& Xing, A.. Equations for the soilwater characteristic curve. Canadian geotechnical journal, 31(4), 521-532, (1994).

24. Migliaro, G.. Il legame costitutivo dei terreni piroclastici per la modellazione di scavi in ambiente urbanizzato ed in-fluenza della parziale saturazione. PhD Thesis, Università degli studi di Salerno (Italy), 305 pages, (2008).

25. Lancellotta, R., Di Prisco, C., Costanzo, D., Foti, S., Sorbino, G., Buscarnera, G., Cosentini, R.M., Foresta, V. Caratterizzazione e modellazione geotecnica. In: Criteri di zona-zione della suscettibilità e della pericolosità da frane innescate da eventi estremi (piogge e sisma). Leonardo Cascini. Composervice srl, Padova, 266-319, (2012).

26. Tonni, L., Gottardi, G., Simonini, P., Pastor, M., \& Mira, P.. Use of Generalized Plasticity to describe the behaviour of a wide class of non-active natural soils. In 3rd International Symposium on Deformation Characteristics of Geomaterials pp. 1145-1153, (2003).

27. Cuomo, S., Manzanal D. Moscariello, M., Pastor M., Foresta V.. Application of a generalized plasticity constitutive model to a saturated pyroclastic soil of Southern Italy. Advances in Soil Mechanics and Geotechnical Engineering. Eds. D. Manzanal \& A. Sfriso. Buenos Aires, IOS Press (2015).

28. Cuomo, S., Moscariello, M., Foresta V., Manzanal D., Pastor M.. Experimental investigation and constitutive modelling for an unsaturated pyroclastic soil Proceedings of Workshop on Volcanic Rocks and Soils, Ischia (Italy), 24-25 September 2016. 